\title{
Borylated Methylenephosphonium salts: the Precursors of Elusive Boryl(Phosphino)carbenes
}

\author{
Florie Lavigne,+ Eddy Maerten,+ Gilles Alcaraz, ${ }^{*}$ Nathalie Saffon-Merceron, $\$$ Carles Acosta-Silva, ${ }^{*}$ \\ Vicenç Branchadell, ${ }^{*}$ Antoine Baceiredo. ${ }^{+, *}$ \\ +Université de Toulouse, UPS, LHFA, 118 route de Narbonne, F-31062 Toulouse, France, and CNRS, LHFA UMR \\ 5069, F-31062 Toulouse, France. ${ }^{\ddagger}$ LCC, UPR CNRS 8241, 205 route de Narbonne, F-31077 Toulouse, France. \\ $\S$ Structure Fédérative de Chimie, FR 2599, 118 route de Narbonne, F-31062 Toulouse, France. ${ }^{\ddagger}$ Departament de \\ Química, Universitat Autònoma de Barcelona, 08193 Bellaterra, Barcelona (Spain).
}

RECEIVED DATE (automatically inserted by publisher); baceired@chimie.ups-tlse.fr

Since the first stable carbenes isolated by Bertrand et al. in 1988 and by Arduengo et al. in 1991, tremendous developments and substantial efforts had been devoted to understand their stabilization and tune their reactivity. ${ }^{1}$ The stabilization and the chemical behavior of these species result from the degree of carbene perturbation that is directly dependant on the substitution pattern at the electron deficient carbon center. ${ }^{2}$ With the exception of the cyclopropenylidene synthesis, ${ }^{3}$ all the examples reported so far involve one amino or phosphino $\pi$-donating substituent (namely push) attached to the carbenic center that defines the two main families of stabilized carbenes. The second substituent determines the nature of the carbene: push-push, push-pull or push-spectator. The carbene synthetic strategy depends strongly on the push-group. The deprotonation route of imidazolium salts initially developed by Arduengo et al. and later extended to the iminium compounds allowed a general access to amino carbenes. ${ }^{4}$ The synthetic approaches involving the weaker $\pi$-donor phosphino group are more limited, the syntheses being mostly ${ }^{5}$ restricted to the decomposition of phosphino diazomethane precursors. $^{6}$ The challenging introduction of an electronwithdrawing group such as boryl substituent at the carbenic center should produce the best model of a push-pull carbene version profiting from the ability of boron to stabilize a lone pair in adjacent position. ${ }^{7}$

As part of our program on group 13 substituted electrondeficient species, we report here the synthesis and characterization of a new class of a boryl phosphino carbocations which provide a synthetic entry to novel and stable boryl(phosphino)carbenes.

Since boryl(phosphino)diazomethane species remain an elusive class of diazo derivatives, ${ }^{8}$ we focused our attention on the possible deprotonation of boryl-substituted methylene phosphonium derivatives, the phosphorus analogues of iminium salts. ${ }^{9}$ Phosphino(boryl)methane $\mathbf{1}$ was synthesized by reaction in THF of (lithiomethyl)dimesitylborane with bis(diisopropylamino) chlorophosphine. Subsequent reaction of $\mathbf{1}$ in toluene with carbon tetrachloride afforded the expected ylide 2 in $66 \%$ overall yield. Stoichiometric amount of gallium trichloride was then used to abstract the chloride from $\mathbf{2}$ in a dichloromethane solution and generate methylene phosphonium salt $3 .^{9 b, c}$ Monitoring the reaction by ${ }^{31} \mathrm{P}$ NMR spectroscopy revealed the complete formation of $3\left({ }^{31} \mathrm{P}: 147 \mathrm{ppm}\right)$ that appeared to be only stable below $-40^{\circ} \mathrm{C}$. Above this temperature, we observed the gradual consumption of $\mathbf{3}$ with the concomitant formation of a new compound that exhibits a signal at $\delta=153 \mathrm{ppm}$. After evaporation of the solvent and workup, the methylenephosphonium isomer $\mathbf{4}$, resulting from an exchange of substituents between boron and phosphorus centers, was isolated (73 \% yield) (Scheme 1). ${ }^{10}$ The identity of isomer $\mathbf{4}$ was unambiguously confirmed by NMR and $\mathrm{X}$-ray diffraction techniques (Figure 1).

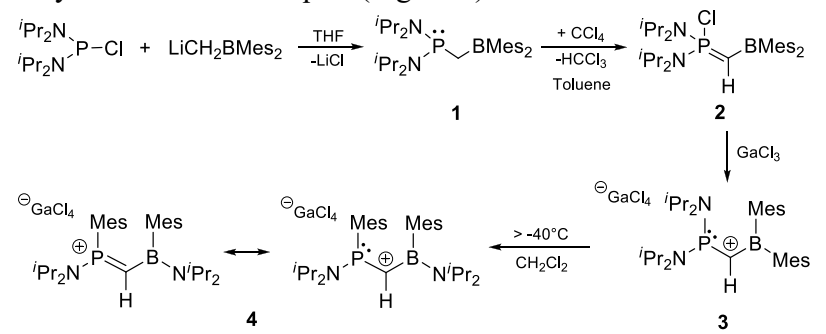

Scheme 1. Synthesis of ylide 2 and methylene phosphonium salts 3 and 4 .

Deprotonation of 4 was carried out in THF at $-80{ }^{\circ} \mathrm{C}$ using a stoichiometric amount of KHMDS (Scheme 2). After evaporation of the solvent and workup, the stable boryl(phosphino)carbene 5 was isolated as yellow crystals from a cold $\left(-40^{\circ} \mathrm{C}\right)$ saturated pentane solution ( $52 \%$ yield), and fully characterized by NMR spectroscopy and X-ray crystallography (Figure 1).

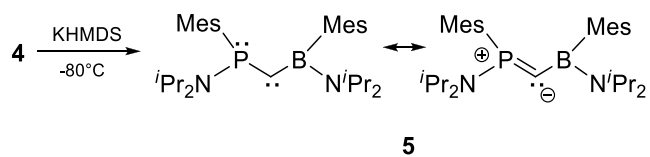

Scheme 2. Synthesis of boryl(phosphino)carbene $\mathbf{5}$.

The ${ }^{31} \mathrm{P}$ NMR spectrum of $\mathbf{5}$ shows a signal at high-field (-36.7 ppm), typical for phosphinocarbenes. ${ }^{2 b}$ The ${ }^{13} \mathrm{C}$ NMR chemical shift for the carbene center appears as a well-resolved doublet at relatively low-field $\left(174.6 \mathrm{ppm},{ }^{1} J_{\mathrm{PC}}=208.9 \mathrm{~Hz}\right)$, and the large coupling constant is indicative of direct $\mathrm{P}-\mathrm{C}$ connectivity. The $\mathrm{X}$ ray structures of $\mathbf{4}$ and $\mathbf{5}$ were determined at $-80{ }^{\circ} \mathrm{C}$ (Figure 1 and Table 1). The phosphorus and the boron atoms are both in a planar environment in planes almost perpendicular $\left(\mathrm{N} 2 \mathrm{PBN} 1=103.1^{\circ}\right)$ for 5 and coplanar for $4\left(\mathrm{~N} 1 \mathrm{BC} 1 \mathrm{P}=172.6^{\circ}\right.$ and $\mathrm{N} 2 \mathrm{PC} 1 \mathrm{~B}=$ $\left.163.2^{\circ}\right)$, respectively. In carbene 5 , the P-C1 (1.563(13) $\AA$ ) distance is shorter than that in $4(1.634(3) \AA)$ and the value is consistent with those reported in the previous phosphinocarbenes (1.53-1.56 $\AA$ ). ${ }^{6 \mathrm{a}, \mathrm{c}, \mathrm{d}}$ The B-C1 bond undergoes a small shortening on going from 4 (1.568(4) $\AA$ ) to 5 (1.54(2) $\AA$ ), but remains long for a BC-double bond. ${ }^{11}$ Thus corroborates to a slightly elongated $\mathrm{N} 1-\mathrm{B}$ bond in 5 (from 1.406(3) in 4 to 1.43(3)) indicative of a competition between the carbene and the nitrogen lone pairs to fulfill the boron vacant orbital.

The large value of the P-C1-B angle, that is wider in 5 $\left(151.6(13)^{\circ}\right)$ than in $4\left(128.6(2)^{\circ}\right)$, is reminiscent of that in phosphino(silyl)carbenes. ${ }^{12}$ 


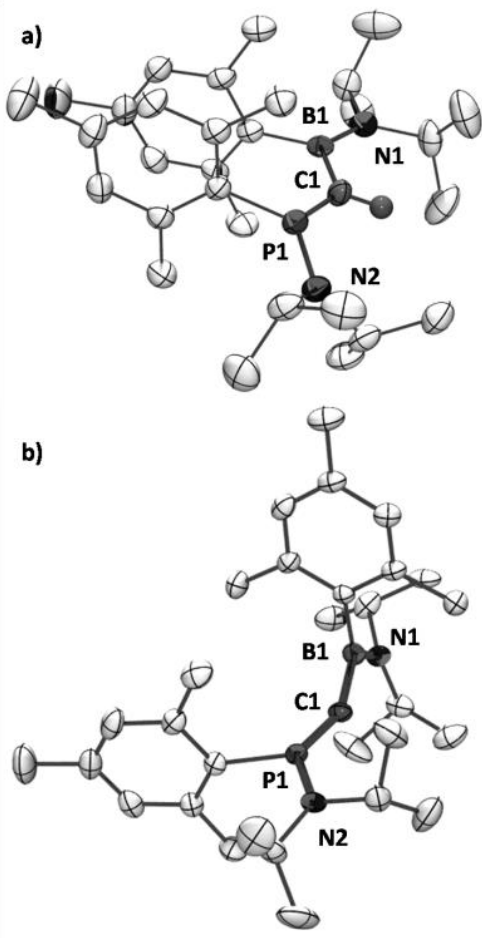

Figure 1. Molecular structures of methylene phosphonium salts 4 (a) and boryl(phosphino)carbene $\mathbf{5}(\mathrm{b})$.

Table 1. Selected geometrical parameters for experimental and optimized structures of $\mathbf{4}$ and $\mathbf{5}$ (Distances in $\AA$, Angles in deg).

\begin{tabular}{ccccc}
\hline & $\mathbf{5}$ & $\mathbf{5}^{\text {calcd }}$ & $\mathbf{4}$ & $\mathbf{4}^{\text {calcd }}$ \\
\hline P-C1 & $1.563(13)$ & 1.569 & $1.634(3)$ & 1.634 \\
B-C1 & $1.54(2)$ & 1.498 & $1.568(4)$ & 1.593 \\
P-C1-B & $151.6(13)$ & 160.2 & $128.6(2)$ & 124.4 \\
\hline
\end{tabular}

The geometries of phosphino(boryl)carbene $\mathbf{5}$ and methylene phosphonium 4 have been optimized at the M05-2X/6-31G(d) level (see Sup. Info.). Despite a P-C1-B angle computed too large for $\mathbf{5}$, as in the case of others P-C-Si carbene analogues, ${ }^{13}$ the other geometrical parameters are reproduced accurately and the optimized geometries of $\mathbf{4}$ and $\mathbf{5}$ are in good agreement with the experimental structures (see Table 1). The bonding nature has been rationalized with a NBO analysis. For carbene $\mathbf{5}$, the analysis shows a P-C triple bond, with the $\pi$ orbital in the P-C1-B plane $(\pi$ ') strongly polarized to $\mathrm{C} 1(88 \% \mathrm{C}$ vs $12 \% \mathrm{P})$. As expected, the perpendicular $2 p$ atomic orbital at boron $\left(\mathrm{LP}^{*}(\mathrm{~B})\right)$ in $\mathbf{4}$ and $\mathbf{5}$ has a relatively large occupancy owing to the $\pi$ donation of the nitrogen lone pair (0.429 e, 5; 0.396 e, 4), with a slight increase upon deprotonation despite a more localized lone pair at the $\mathrm{N} 1$ atom $(1.706 \mathrm{e}, 5 ; 1.623 \mathrm{e}, 4)$. Indeed, the analysis of the donor-acceptor interactions in the NBO basis estimated from second order perturbation theory shows that, in the case of carbene $\mathbf{5}$, the donations $\mathrm{LP}(\mathrm{N} 1)$ and $\pi^{\prime}(\mathrm{C} 1-\mathrm{P})$ to $\mathrm{LP}^{*}(\mathrm{~B})$ are of comparable magnitude. This feature is illustrated in $\mathbf{5}$ by a rotation of the boron plane favoring the interaction between the carbene lone pair $(\pi$ '(C1-P)) with the vacant LP*(B) orbital at boron. Finally, the variations of Wiberg bond indices around the carbenic center on going from 4 to $5(\mathrm{P}-\mathrm{C} 1,+0.33$; $\mathrm{C} 1-\mathrm{B},+0.25)$ confirm that $\mathbf{5}$ can be classified as a push-pull-carbene. As expected for this type of carbene, the singlet-triplet energy gap was predicted to be relatively small $(17.7 \mathrm{kcal} / \mathrm{mol}){ }^{2 \mathrm{~b}}$

Carbene $\mathbf{5}$ is perfectly stable in the solid state and slowly rearranges in solution into the corresponding phosphaalkene 6 involving a 1,2-migration of the mesityl group from the phosphorus to the central carbon atom (Scheme 3).

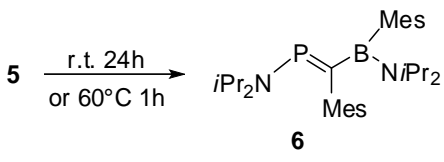

Scheme 3. Synthesis of phosphaalkene 6.

More than twenty years after the isolation of the first stable carbene, the existence of a stable boryl(phosphino)carbene has been clearly demonstrated. An original synthetic pathway, starting from boryl-substituted methylene phosphonium derivatives, has been developed, and should provide a promising alternative to the classical phosphinodiazomethane precursors. Developments of new models allowing a more complete understanding of this new family of carbenes are under active investigation.

Acknowledgments: This work was supported by the CNRS (LEA 368), Spanish Ministerio de Ciencia e Innovación (CTQ2007-61704/BQU) and Generalitat de Catalunya (2009SGR733 and XRQTC). Time allocated in the Centre de Supercomputació de Catalunya (CESCA) is gratefully acknowledged.

Supporting Information Available: Experimental procedures, selected NMR data, X-ray crystallographic files for 4 and 5 (CIF); computational details and Cartesian coordinates for the structures calculated. This material is available free of charge via the Internet at http://pubs.acs.org.

References

(1) (a) Igau, A.; Grutzmacher, H.; Baceiredo, A.; Bertrand, G. J. Am. Chem Soc. 1988, 110, 6463. (b) Arduengo, A. J.; Harlow, R. L.; Kline, M. $J$ Am. Chem. Soc. 1991, 113, 361. (c) Bourissou, D.; Guerret, O.; Gabbai, F. P.; Bertrand, G. Chem. Rev. 2000, 100, 39.

(2) (a) Canac, Y.; Soleilhavoup, M.; Conejero, S.; Bertrand, G. J Organomet. Chem. 2004, 689, 3857. (b) Vignolle, J.; Cattoën, X.; Bourissou, D. Chem. Rev. 2009, 109, 3333. (c) Kato, T.; Maerten, E.; Baceiredo, A. In Transition Metal Complexes of Neutral $\eta^{l}$-Carbon Ligands; XI ed.; Chauvin, R., Canac, Y., Eds. 2010; Vol. 30, p 131.

(3) (a) Lavallo, V.; Canac, Y.; Donnadieu, B.; Schoeller, W. W.; Bertrand, G Science 2006, 312, 722. (b) Schoeller, W. W.; Frey, G. D.; Bertrand, G. Chem. Eur. J. 2008, 14, 4711.

(4) N-Heterocyclic Carbenes in Transition Metal Catalysis, Glorius, F. ed; Springer, 2006; Vol. 21 p. 231

(5) Martin, D.; Baceiredo, A.; Gornitzka, H.; Schoeller, W. W.; Bertrand, G. Angew. Chem., Int. Ed. 2005, 44, 1700.

(6) (a) Soleilhavoup, M.; Baceiredo, A.; Treutler, O.; Ahlrichs, R.; Nieger, M.; Bertrand, G. J. Am. Chem. Soc. 1992, 114, 10959. (b) Treutler, O. Ahlrichs, R.; Soleilhavoup, M. J. Am. Chem. Soc. 1993, 115, 8788. (c) Buron, C.; Gornitzka, H.; Romanenko, V.; Bertrand, G. Science 2000 , 288, 834. (d) Despagnet, E.; Gornitzka, H.; Rozhenko, A. B.; Schoeller, W. W.; Bourissou, D.; Bertrand, G. Angew. Chem., Int. Ed. 2002, 41 2835. (e) Despagnet-Ayoub, E.; Gornitzka, H.; Bourissou, D.; Bertrand, G. Eur. J. Org. Chem. 2003, 2039.

(7) (a) Pelter, A.; Singaram, B.; Wilson, J. W. Tetrahedron Lett. 1983, 24, 631. (b) Cooke, M. P. J. Org. Chem. 1994, 59, 2930. (c) Pelter, A. Pure \& Appl. Chem. 1994, 66, 223.

(8) Only a few boryldiazomethane derivatives have been described: (a) Arthur, M.P.; Baceiredo, A.; Bertrand, G. J. Am. Chem. Soc. 1991, 113 , 5857; (b) Weber, L.; Wartig, H. B.; Stammler, H-G; Neumann, B. Organometallics 2001, 20, 5248 .

(9) (a) Igau, A.; Baceiredo, A.; Grützmacher, H.; Pritzkow, H., Bertrand, G. J. Am. Chem. Soc. 1989, 111, 6853. (b) Grützmacher, H.; Pritzkow, H. Angew. Chem., Int. Ed. 1991, 30, 709. (c) Heim, U.; Pritzkow, H. Schönberg, H.; Grützmacher, H. Chem. Comm. 1993, 673

(10) Species $\mathbf{3}$ and $\mathbf{4}$ can be regarded as electron deficient $\alpha$ borylcarbocations. Calculations (M05-2X/6-31G(d) level) reveal isomer 4 is $29.9 \mathrm{kcal}_{\mathrm{mol}}{ }^{-1}$ more stable than isomer 3 suggesting an increased stabilization owing to the $\pi$ donation from LP(N2) to LP*(B) in 4

(11) (a) Horchler von Locquenghien, K.; Baceiredo, A.; Boese, R.; Bertrand, G. J. Am. Chem. Soc. 1991, 113, 5062. (b) Chiu, C.-W.; Gabbaï, F. P. Angew. Chem., Int. Ed. 2007, 46, 6878.

(12) Kato, T.; Gornitzka, H.; Baceiredo, A.; Savin, A.; Bertrand, G. J. Am. Chem. Soc. 2000, 122, 998.

(13) (a) Martin, D.; Illa, O.; Baceiredo, A.; Bertrand, G.; Ortuno, R. M.; Branchadell, V. J. Org. Chem. 2005, 70, 5671. (b) Lecea, B.; Ayerbe, M.; Arrieta, A.; Cossío, F. P.; Branchadell, V.; Ortuño, R. M.; Baceiredo, A J. Org. Chem. 2007, 72, 357. 
